\title{
DETERMINATION OF OPTIMAL PARBOILING CONDITIONS FOR NIGERIAN FARO-44 RICE VARIETY
}

\author{
A. B. Muochebe ${ }^{1}$, O. C. Nwajinka ${ }^{2, *}$ and I. E. Nwatu ${ }^{3}$ \\ 1, 2, 3, DePARTMENT OF AGRIC AND BIORESOURCES ENGINEERING, NNAMDi AZIKIWE UNIVERSITY, AWKA, \\ ANAMBRA STATE, NIGERIA \\ E-mail addresses: ${ }^{1}$ muochebebonaventure@gmail.com, ${ }^{2}$ oc.nwajinka@unizik.edu.ng, \\ 3 nsnwatu@gmail.com
}

\begin{abstract}
Optimization study was carried out on the parboiling process variables for improving the milling quality of FAR 0-44 rice variety using Response Surface Methodology (RSM) in Central Composite Design (CCD). The variables studied were initial soaking temperature (IST), soaking time (SKt) and steaming time (STt) including their interactive effects. The range of the input variables studied were $70-90^{\circ} \mathrm{C}$, 8-12hrs and 40-50minsfor initial soaking temperature, soaking time and steaming time respectively. For thisstudy, a total of twenty (20) randomized experimental runs comprising one (1) replicate of factorial point, one (1) replicate of axial point (alpha 2.7) and six (6) centre point in the design space. Analyses of variance (ANOVA) were performed on the experimental data sets and models were fitted for all the response variables generated.The result showed that the optimal parboiling variables were, $90^{\circ} \mathrm{C}, 46 \mathrm{mins}$ and 10 hours, for initial soaking temperature, steaming time and soaking time respectively with their corresponding optimum response $58.7 \%, 6.7 \%$ and $58.1 \%$ for Head rice yield (based on parboiled paddy weight), breakage ratio and milled rice colour (based on illumination). The composite desirability is 0.793 which maximized the percentage Head rice yield (HRY) and milled rice colour (MRC) but minimized the percentage Breakage Ratio (BR).
\end{abstract}

Keywords: optimization, Response Surface Methodology, FARO-44, Rice,Head rice, parboiling

\section{INTRODUCTION}

Rice is one of Nigeria's most important crops which occupies a significant proportion of the government's strategic efforts in tackling food shortages through various national programmes and agencies [1]. It is a staple food and has the potential of becoming a major export commodity in near future [2]. It is eaten as whole-grain and can be converted to flour and subsequently reconstituted in hot water into paste and eaten with soup known as tuwoshinkafa in Northern Nigeria.

Nigeria is West Africa's biggest rice producer, generating an equivalent of 3.2 million tonnes of paddy rice ( 2 million tonnes of milled rice) over the previous 7 years [3]. Previously, Domestic supply has not been able to match with consumers' demand in Nigeria with a population of about two hundred million (200 million) people [4]. This has resulted in continued rise in import of this commodity over the years and thereby prompting the Federal government to place a ban on importation of rice in $2015[5,6]$.

The desirability for exported rice will largely depend on the quality attributes of its processed form, which in turn depends on the process variables adopted by the processors. The non-competitiveness of Nigerian rice with foreign counterpart is mainly as a result of the use of outdated and inefficient process and technology in the unit operations (particularly parboiling) which leads to odour, unattractive products appearance, existence of stones, irregular grains sizes and to some large extent agronomic practice [7]. All these impact the performance of milled rice, therefore it is through process

* Corresponding author, tel: $+234-803-668-9930$ 
optimisation that best process input variables can be determined.

Parboiling is a unit operation in rice processing in which the rice grain turns from crystalline structure into an amorphous state [8]. It is a vital part of rice processing and has so many advantages as it improves physical properties of rice as well as its economic value which includes improved insect resistance, easy rice milling, better storage properties and increased product value [9]. Parboiling involves temporary heating of the paddy before milling to enhance its nutritional significance and change the texture and subsequently reduce the breakages during milling [10]. Parboiled white rice is $80 \%$ nutritionally similar to brown rice [11]. Parboiling results in significant changes in the physical and chemical characteristics of rice grain.Soaking, Steaming and drying are the fundamental pretreatments (unit operations of rice processing) before milling. These measures also leave rice simpler to handle by hand, increase its dietary value and alter its physical properties [12].

Several studies have been performed on the impact of parboiling unit operation (soaking time, initial soaking temperature, steaming time and drying time) on rice performance [13 - 17]. Some of these studies were carried out on different varieties in other countries and do not match the prevalent varieties in Nigeria, which is FARO-44.

It is essential to remember that the effectiveness of the parboiling procedure has a significant impact on the technical results of the milling process and therefore on the overall quality of the rice as well as on the market value of the final product.

Parboiling method used in most part of Nigeria by rice processors includes the use of direct heating in pots $[18,19]$, which has proven to be inefficient as its physical qualities are affected by the presence of high breakage ratio, poor physical appearance and variegated colours. Because of the ineffectiveness of the direct pot cooking, false bottom method was introduced as an improvement $[20,21]$. It consists of a pot with a false floor made of a perforated metal sheet on which the rice paddy is placed thereby elevating above the water level in the pot to prevent direct heating.

It is the inefficiency of this process that led to the consideration of the steaming method whereby the rice paddy is placed in a container while steam is generated in a boiler and transported to the steaming tank. It is the objective of this paper to determine the optimal process variables for parboiling of FARO-44 rice variety in Nigeria using locally fabricated steam parboiler.

\section{MATERIALS AND METHODS}

\subsection{Materials Procurement and Preparation}

Raw paddy that was used in this study is FARO 44 rice variety which is one of the most popular varieties in Nigeria. It was obtained from local farmers in Ayamelum L.G.A., Anambra State, Nigeria. The raw paddy was manually cleaned to remove stones and other foreign materials by immersing in water and removing those that were floatting on water.

\subsection{On-site Parboiling Method}

The details of the steam parboiler used in the experiments are graphically presented in Figures 1 and 2 . A $25 \mathrm{~kg}$ of paddy rice sample was put into each steaming tank. The samples were soaked in water of different temperature for a specified period of time as part of the pre-treatments as specified in the experimental design. Steaming was done when the boiling temperature was about $100^{\circ} \mathrm{C}$,by allowing steam to pass through the hose into the steaming tank, [22]. A constant steaming temperature of $90^{\circ} \mathrm{F}$ $\left(32.2^{\circ} \mathrm{C}\right)$ was achieved within the tank that contains the already soaked paddy sample for a stipulated amount of time. After steaming, the rice grains were dried under the sun for two (2) days at an average temperature of $\pm 32^{\circ} \mathrm{C}$. A milling machine (Model S1115NMB) equipped with prime mover of 22 horsepower with a speed of 2200rpm was used to de-husk the $25 \mathrm{~kg}$ of dried parboiled rice paddy sample.

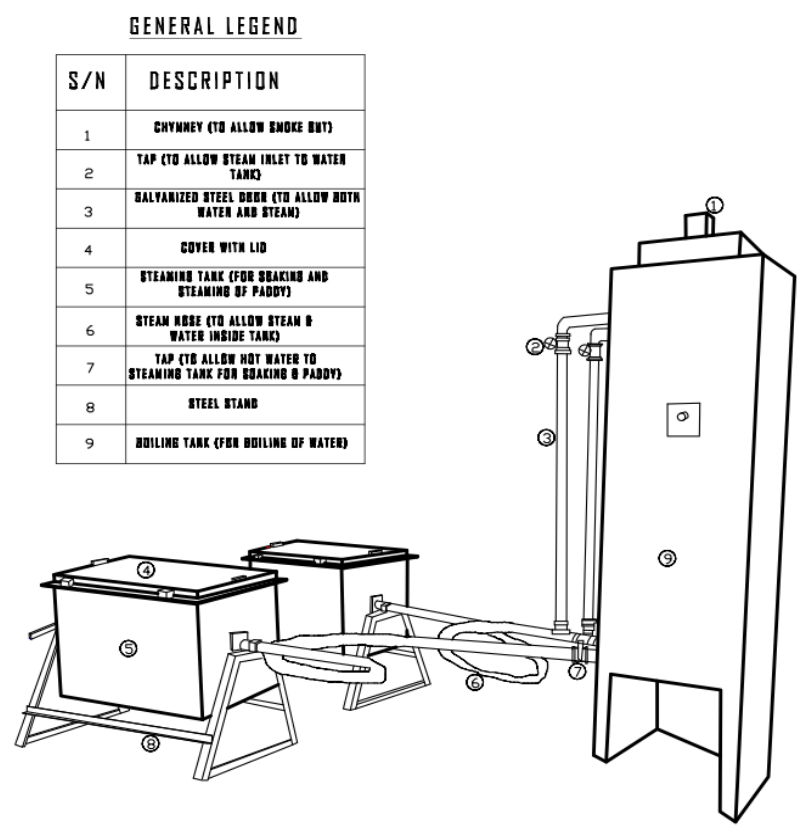

Figure 1. Assembly of the Steam Parboiler. 


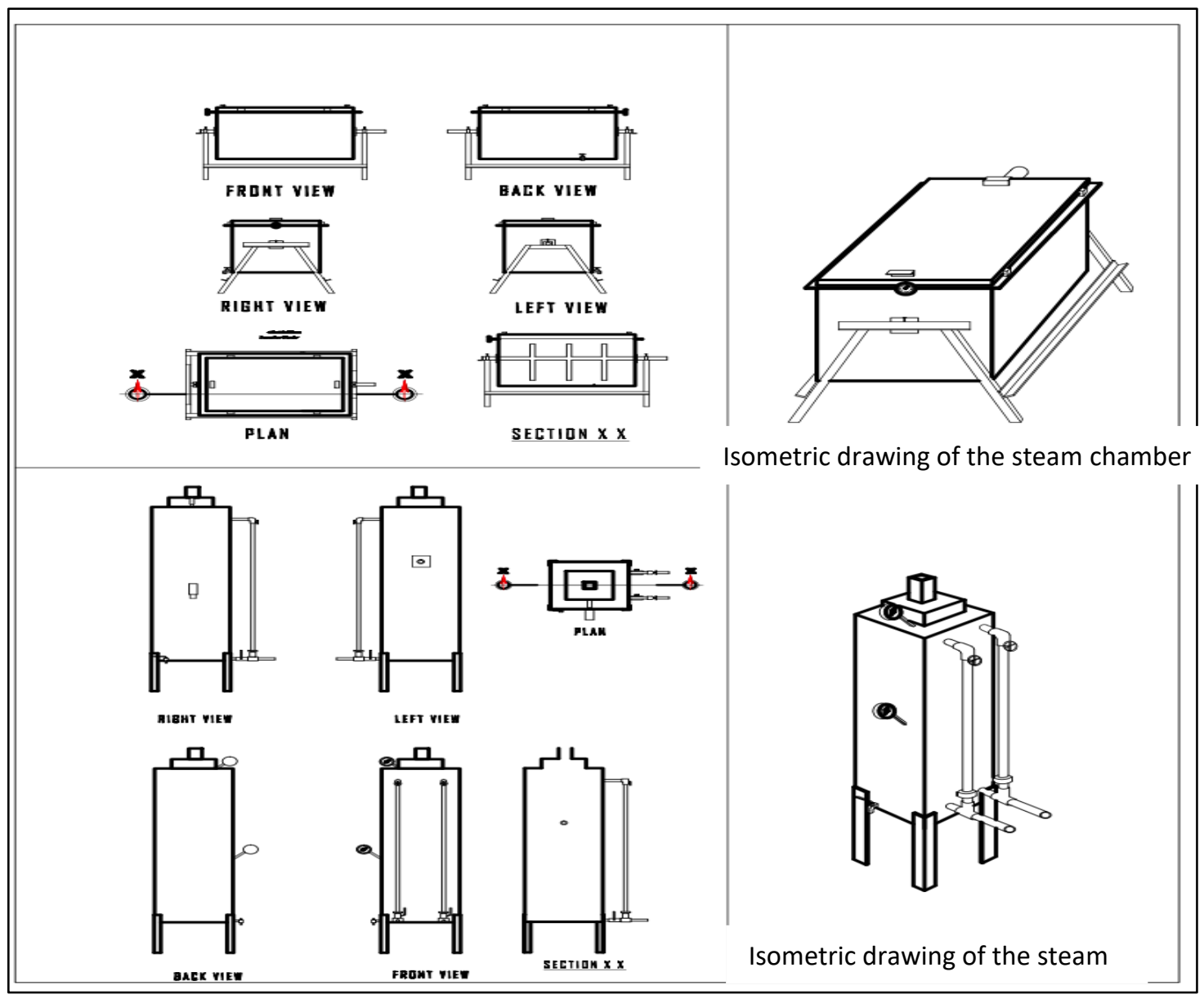

Fig.2. Orthographic projections of the steam parboiler

The dried parboiled paddy rice was weighed and recorded before and after milling. The milled rice was subsequently graded by a grading machine (Model MMJP63 $\times 3$ ) to obtain the recovered head rice and broken rice respectively.

\subsection{Experimental Design}

For the optimization study, Response Surface Methodology (RSM) in central composite design (CCD) was adopted to optimize the selected parboiling process variables for improved head rice yield. The three input variables ranges were obtained from pre-experimental trials guided by literature as follows, Soaking Temperature (SKT) from $70^{\circ} \mathrm{C}$ to $90^{\circ} \mathrm{C}$, Soaking Time (SKt) ranging from $8 \mathrm{hrs}$ to $12 \mathrm{hrs}$, and Steaming Time (STt) ranging from $40 \mathrm{mins}$ to 50 mins. These combinations generated twenty (20) experimental runs including one (1) factorial point, one (1) axial point (alpha 2.7) and six (6) centre points in the design matrix.

\subsection{Determination of Quality Attributes.}

The Head Rice Yield (\%), Breakage Ratio (\%), and Milled Rice Colour (\%) were determined and under the studied parboiling parameters.

\subsubsection{Head rice yield}

The milling equipment used in this study had the capability of separating whole and broken grains. The HRY was calculated as a percentage using equation 1.

$$
\begin{aligned}
& \text { Head Rice Yield (\%) } \\
& =\frac{\text { Weight of WMG }(\mathrm{g})}{\text { Total weight of dried parboiled paddy }(\mathrm{g})} \times 100
\end{aligned}
$$

\subsubsection{Percentage Breakage Ratio (PBR)}

Milled rice was graded and separated using a grading machine and the broken kernel was separated from the whole grains. The percentage of the broken grains was computed using equation 2.

$$
P B R=\frac{\text { Weight of broken grains }}{\text { Total weight of paddy samples }} \times \frac{100}{1}
$$




\subsubsection{Milled Rice Colour}

Spectrophotometer, 721-VIS model, was used to determine the MRC determination utilizing the $L^{*}$, $a^{*}, b^{*}$ uniform colour space procedure. $L^{*}$ indicates lightness while $a *$ and $b^{*}$ are chromaticity coordinates. $a^{*}$ and $b^{*}$ are colour directions: $+a^{*}$ is the red axis, $-a^{\prime}$ is the green axis, $+b^{*}$ is the yellow axis and $-b^{*}$ is the blue axis. The results for $a^{*}$ and $b^{*}$ were collected in duplicate and the colour index of the mean was calculated as shown in equation 3.

$$
\text { Milled Rice Colour }=\sqrt{(a *)^{2}+(b *)^{2}}
$$

\section{RESULTS AND DISCUSSION}

\subsection{Data Analysis and Model Development}

Table 1 shows the factor combinations and corresponding responses in the design matrix.

The experimental data were subjected to statistical analysis using Design expert (version 11 softwae 2011, Stat-Ease Co., USA) which was used in the experimental design.

\subsection{Head Rice Yield (HRY)}

A Quadratic model was developed as the most fitted model for HRY as afactor of the Soaking Temperature (SKT), Soaking Time (SKt) and
Steaming Time (STt).From the model, an increase in SKT, SKtand STt would lead to increase in HRY. The SKt had a stronger effect on the Head Rice Yield than SKT and STt, while the quadratic term of soaking time (SKt) ${ }^{2}$ had a negative effect on the Head rice yield as seen in equation 4 .

$$
\begin{aligned}
\mathrm{HRY}=-85.77480 & +0.201616 * \mathrm{STt}+23.61949 \\
& * \mathrm{SKt}+0.128873 * \mathrm{SKT}-1.12792 \\
& * \mathrm{SKt}^{2}
\end{aligned}
$$

The observed value for HRY ranges from 43 to $59.79 \%$. This finding did not differ much from the report of other researchers who reported HRY of $62.13 \%$ to $68.13 \%$ [17], $65.9 \%$ to $70.9 \%$ [15], $60.8 \%$ to $73.88 \%$ [14] and $30.11 \%$ to $75.76 \%$ [13]. The observed deviations could be due to variations in rice varieties, climate or experimental error.

The goodness of fit of the model was further confirmed by the coefficient of correlation $\left(R^{2}\right)$, adjusted $R^{2}$ and predicted $R^{2}$ value of $0.95,0.94$ and 0.91 respectively. Table 2 shows the analysis of variance (ANOVA) results for the experimental data. The ANOVA table indicates that the Quadratic model is significant at $p<0.05$. The developed model equation in terms of actual factors is given in equation (3).

\section{Table 1: Experimental Design Matrix}

\begin{tabular}{cccccccc}
\hline Std & Run & $\begin{array}{c}\text { Factor } 1 \\
\text { A: } \\
\text { Steaming } \\
\text { Time (min) }\end{array}$ & $\begin{array}{c}\text { Factor 2 } \\
\text { B: } \\
\text { Soaking } \\
\text { Time (hrs) }\end{array}$ & $\begin{array}{c}\text { Factor 3 } \\
\text { C: Initial Soaking } \\
\text { Temperature } \\
\left({ }^{\circ} \text { C) }\right.\end{array}$ & $\begin{array}{c}\text { Response 1 } \\
\text { Head Rice } \\
\text { Yield (\%) }\end{array}$ & $\begin{array}{c}\text { Response 2 } \\
\text { Breakage } \\
\text { Ratio (\%) }\end{array}$ & $\begin{array}{c}\text { Response 3 } \\
\text { Milled Rice } \\
\text { Colour (\%) }\end{array}$ \\
\hline 14 & 1 & 40 & 12 & 90 & 55.0 & 10.0 & 65.1 \\
19 & 2 & 50 & 12 & 90 & 57.0 & 13.0 & 63.8 \\
10 & 3 & 40 & 8 & 90 & 50.0 & 11.0 & 55.0 \\
17 & 4 & 50 & 8 & 90 & 51.9 & 14.5 & 60.0 \\
1 & 5 & 50 & 12 & 70 & 54.9 & 16.3 & 52.0 \\
20 & 6 & 40 & 12 & 70 & 51.9 & 18.9 & 50.0 \\
15 & 7 & 50 & 8 & 70 & 51.8 & 21.4 & 57.6 \\
6 & 8 & 40 & 8 & 70 & 49.1 & 19.5 & 54.7 \\
4 & 9 & 45 & 10 & 63 & 53.0 & 13.8 & 53.0 \\
2 & 10 & 45 & 10 & 97 & 59.8 & 7.9 & 52.0 \\
13 & 11 & 37 & 10 & 80 & 56.6 & 10.0 & 58.8 \\
8 & 12 & 45 & 10 & 80 & 55.6 & 9.1 & 54.9 \\
7 & 13 & 45 & 10 & 80 & 56.8 & 13.0 & 59.0 \\
5 & 14 & 53 & 10 & 80 & 58.9 & 17.0 & 55.8 \\
12 & 15 & 45 & 13 & 80 & 50.0 & 15.5 & 58.0 \\
18 & 16 & 45 & 7 & 80 & 43.0 & 23.0 & 65.0 \\
3 & 17 & 45 & 10 & 80 & 57.0 & 6.0 & 66.0 \\
11 & 18 & 45 & 10 & 80 & 56.0 & 10.0 & 67.0 \\
16 & 19 & 45 & 10 & 80 & 57.2 & 9.3 & 66.0 \\
9 & 20 & 45 & 10 & 80 & 58.2 & 5.7 & 48.9 \\
\hline
\end{tabular}


Table 2: ANOVA Table for Head Rice Yield

\begin{tabular}{lllllll}
\hline Source & $\begin{array}{l}\text { Sum of } \\
\text { Squares }\end{array}$ & df & $\begin{array}{l}\text { Mean } \\
\text { Square }\end{array}$ & F-value & p-value & \\
\hline Model & 302.43 & 4 & 75.61 & 72.97 & $<0.0001$ & significant \\
A-Steaming Time & 13.33 & 1 & 13.33 & 12.87 & 0.0027 & \\
B-Soaking Time & 56.30 & 1 & 56.30 & 54.33 & $<0.0001$ & \\
C-Initial Soaking Temperature & 22.89 & 1 & 22.89 & 22.09 & 0.0003 & \\
B $^{2}$ & 209.91 & 1 & 209.91 & 202.58 & $<0.0001$ & \\
Residual & 15.54 & 15 & 1.04 & & & \\
Lack of Fit & 11.19 & 10 & 1.12 & 1.29 & 0.4125 & not significant \\
Pure Error & 4.35 & 5 & 0.8704 & & & \\
Cor Total & 317.97 & 19 & & & & \\
\hline
\end{tabular}

Under post analysis, the point prediction gave percentage HRYof $57 \%$ with $56.4 \%$ low and $57.7 \%$ high at $95 \%$ CI. This implies that we are $95 \%$ confident that the mean HRY of faro-44 rice variety is between $56.4 \%$ and $57.7 \%$ under the optimized process conditions. The standard error of the mean was 0.3 which was low enough.

Surface response plots for HRY obtained from design expert are shown in Fig. 4 to 6 . The interactions among the three independent variables were studied to maximize the percentage HRY. Fig. 4 shows the 3D representation of the interaction between initial soaking temperature and soaking time. HRY was significantly improved by increasing initial soaking temperature and soaking time up to $10-11 \mathrm{hrs}$ at maximum steaming time.

The effect of initial soaking temperature and steaming time is shown in Fig.5. The interaction shows that HRY increased with increasing initial soaking temperature and steaming time.

The effect of steaming and soaking time is shown in Fig. 6. The interaction shows that HRY increases steadily with increase in steaming time and increase in soaking time up to $10-11 \mathrm{hrs}$ at maximum initial soaking temperature. A further increase in soaking time beyond $11 \mathrm{hrs}$ led to decrease in HRY because paddy rice absorbs excessive water of which during steaming would affect the gelatinization of starch. HRY was found to be minimal at the lowest soaking and steaming time as shown in Fig. 6 .

\subsection{Breakage Ratio (BR)}

The Quadratic model was selected by the software as most suitable for BR as a factor of the Initial Soaking Temperature (IST), Soaking Time (SKt) and Steaming Time (STt). Model reduction through backward selection based on an alpha level of $a=0.1$ was applied to remove non-significant terms from the model.
$\mathrm{STt}, \mathrm{STt}^{2}$, and $\mathrm{SKt}^{2}$ all had a positive effect on $\mathrm{BR}$, which indicates that an increase in those terms would lead to an increase in BR. The observed value for BR ranges from 5.7-23\%, with Sample R20 having the least BR and Sample R16 having the most $B R$. The findings varied significantly from the report of Ogunbiyiet al.,[15] (2018) who reported between 1.80 and $3.40 \%$. The observed difference may be due to variation in rice variety as he used FARO-52 as his experimental sample and experimental conditions.

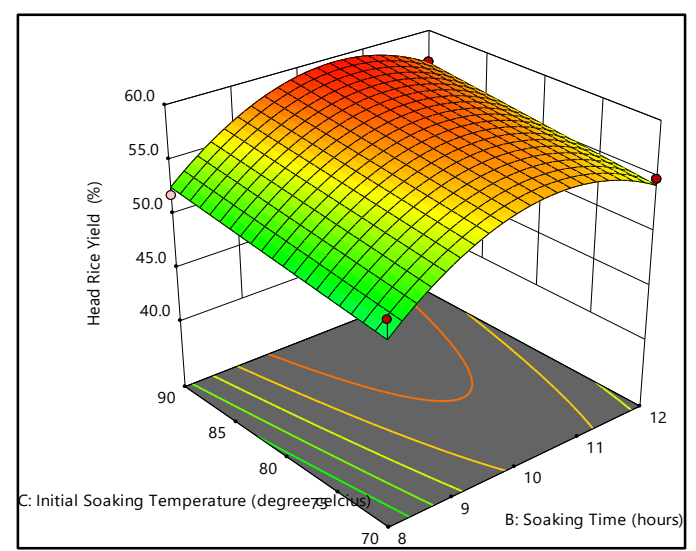

Figure 4: Effect of initial soaking temperature and soaking time on HRY

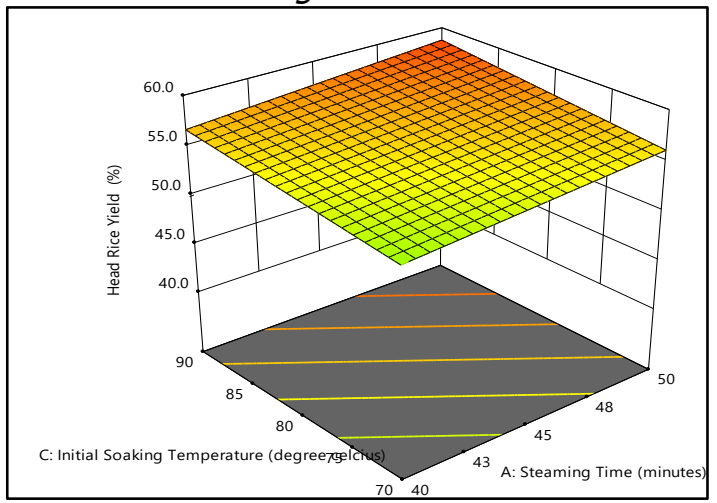

Figure 5: Effect of initial soaking temperature and steaming time on HRY

The goodness of fit of the model was estimated by the coefficient of correlation $\left(R^{2}\right)$, adjusted $R^{2}$ and 
predicted $\mathrm{R}^{2}$ value of $0.8314,0.7711$ and 0.6627 respectively at $95 \% \mathrm{CI}$.

Point prediction gave percentage BR of $9.4 \%$ with $7.6 \%$ low and $11.2 \%$ highat $95 \%$ CI. This implies that there is $95 \%$ confidence that the mean BR of faro- 44 rice variety is between $7.6 \%$ and $11.2 \%$. The standard error of the mean was 0.8 which was low enough.

Table 3 shows the analysis of variance (ANOVA) for the reduced Quadratic model. The ANOVA indicated that the Quadratic model can significantly predict the response variables at $95 \% \mathrm{CI}(p<0.05)$. The final Quadratic model based on theactual factors is given in equation 4.

Breakage Ratio (BR)

$$
\begin{aligned}
& =274.77242-5.77782 \times \mathrm{STt} \\
& -23.08164 \times \mathrm{SKt}-0.273339 \times \mathrm{IST} \\
& +0.067045 \times \mathrm{STt}^{2}+1.11508 \\
& \times \mathrm{SKt}^{2}
\end{aligned}
$$

Surface response plot for BR obtained from design expert is shown in Fig. 7. The factor interactions among the three independent variables that minimized Breakage Ratio was studied. Fig.7 shows the 3D-plot of the interactions between steaming time and soaking time. BR decreased as steaming time increased up to 44 mins but afterwards increased as steaming time continues to increase. BR decreased as the soaking time increase up to $10 \mathrm{hrs}$ but increased as soaking time increases beyond 10hrs. BR decreases linearly as initial soaking temperature increases. In summary, BR increased with increased steaming time, lower soaking time and lower initial soaking temperature as shown in Fig. 7.

\subsection{Milled Rice Colour (MRC)}

Data for the milled Rice Color in relation tothe Initial Soaking Temperature (IST), Soaking Time (SKt) and Steaming Time (STt) were analysed using the design expert v. 11 software. Curiously, there was no observed relationship between the MRC and the process variables studied as shown in Table 4.

This is in agreement with a report made by Widyasaputraet al. (2019) on milled rice colour. This explains why it's difficult to ascertain the colour differences between samples by virtual observations. However, the observed value for MRC ranges from 48.9-67\%, with Sample R18 having the most observed MRC and Sample R20 having the least colour value as shown in table 1 . Table 4 shows the analysis of variance (ANOVA) for MRC.

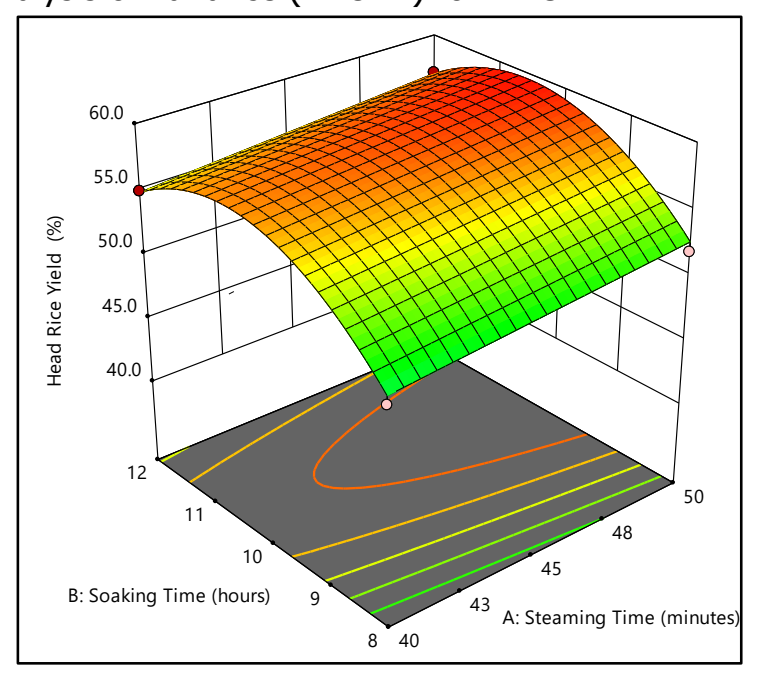

Figure 6: Effect of soaking time and steaming time on $H R Y$

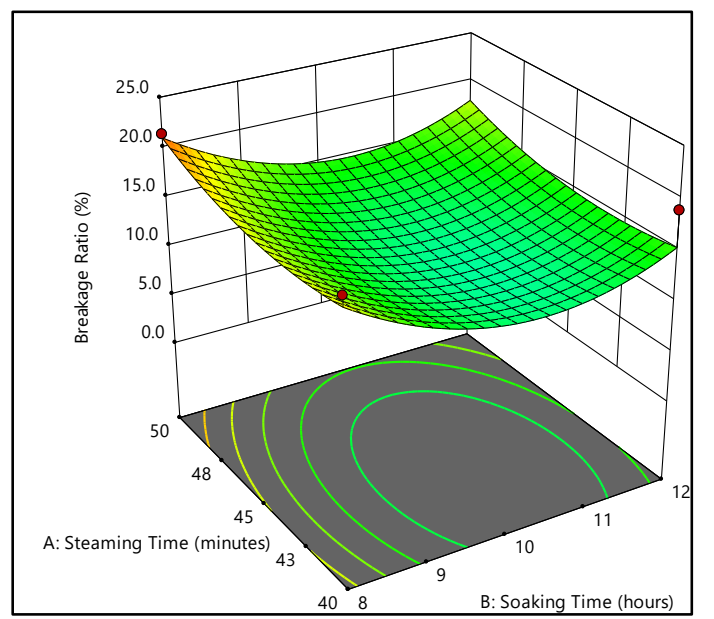

Figure 7: Effect of steaming time and soaking time on $B R$

Table 3: ANOVA Table for Breakage Ratio

\begin{tabular}{lcccccc}
\hline \multicolumn{1}{c}{ Source } & Sum of & df & Mean & F-value & p-value & \\
& Squares & & Square & & \\
\hline Model & 392.19 & 5 & 78.44 & 13.80 & $<0.0001$ & significant \\
A-Steaming Time & 21.53 & 1 & 21.53 & 3.79 & 0.0720 & \\
B-Soaking Time & 30.42 & 1 & 30.42 & 5.35 & 0.0364 & \\
C-Initial Soaking & 102.96 & 1 & 102.96 & 18.12 & 0.0008 & \\
Temperature & 35.11 & 1 & 35.11 & 6.18 & 0.0262 & \\
$\mathrm{~A}^{2}$ & & & & & & \\
\hline
\end{tabular}


Determination of Optimal Parbolling Conditions for Nigerian FARO-44 Rice Variety, A. B. Muochebe, O. C. Nwajinka \& I. E. Nwatu

\begin{tabular}{lcccccc}
\hline \multicolumn{1}{c}{ Source } & $\begin{array}{c}\text { Sum of } \\
\text { Squares }\end{array}$ & $\mathrm{df}$ & $\begin{array}{c}\text { Mean } \\
\text { Square }\end{array}$ & F-value & p-value & \\
\hline $\mathrm{B}^{2}$ & 205.10 & 1 & 205.10 & 36.09 & $<0.0001$ & \\
Residual & 79.55 & 14 & 5.68 & & & not \\
Lack of Fit & 42.53 & 9 & 4.73 & 0.6382 & 0.7372 & significant \\
& 37.02 & 5 & 7.40 & & & \\
Pure Error & 471.74 & 19 & & & & \\
Cor Total & & & & & & \\
\hline
\end{tabular}

Table 4: ANOVA Table for Milled Rice Colour

\begin{tabular}{lrrrrrr}
\hline \multicolumn{1}{c}{ Source } & Sum of Squares & \multicolumn{1}{c}{ df } & Mean Square & F-value & p-value & \\
\hline Model & 0.0000 & 0 & & & & \\
Residual & 625.52 & 19 & 32.92 & & & \\
Lack of Fit & 354.84 & 14 & 25.35 & 0.4682 & 0.8790 & not significant \\
Pure Error & 270.68 & 5 & 54.14 & & & \\
Cor Total & 625.52 & 19 & & & & \\
\hline
\end{tabular}

According to Taghinezhadet al. [17] and Yousafet al. [14] milled rice colour is affected most by steaming and drying times due to higher diffusion of colour pigment from the bran and hull into the endosperm. Also, amino acid milliard reaction present in rice grain has been attributed to influence the colour value of rice as reported by Taghinezhadet al. [17]. These literature evidences support the claim that the MRC is affected by the factors beyond the ones studied in this work.

\subsection{Numerical Optimizations}

The main objective of this work was to obtain the optimal parboiling conditions in terms of Soaking Temperature(SKT), Soaking Time (SKt), Steaming Time (STt)and Initial Soaking Time (ISt) in relation to Head Rice Yield (HRY), Breakage Ratio (BR) and Milled Rice Colour (MRC). The optimization goals are:

i. Maximize Percentage Head Rice Yield (HRY)

ii. Minimize percentage Breakage Ratio (BR)

iii. Maximize Percentage of Milled Rice Colour (MRC)

In Design expert v.11, 0 is minimum desirability while 1 is maximum desirability. The optimal parboiling conditions is determined based on the maximum desirability obtained.

Based on the data analysis, the predicted optimum condition is $46 \mathrm{mins}, 10$ hours and $90^{\circ} \mathrm{C}$ for STt, SKt and IST respectively with desirability index of 0.793 . The above optimum parboiling condition for FARO44 rice variety would produce a percentage Head Rice Yield as high as $58.7 \%$, a minimal breakage ratio of $6.7 \%$ and a milled rice colour of 58.1 .

\section{CONCLUSION}

This research was to improve the physical quality and economic value of rice by local rice processors. Based on the study the predicted optimum soaking temperature, steaming time and soaking time were $90^{\circ} \mathrm{C}, 46 \mathrm{mins}$ and 10 hours respectively. Under this optimum parboiling condition, the Head rice yield was $58.7 \%$ (based on parboiled paddy weight), breakage ratio was $6.7 \%$ and milled rice colour was 58.1 illumination at composite desirability of 0.793 . Increase in soaking time above the optimum conditions led to a gradual decline in Head Rice Yield, while increase in steaming time, however, had no significant effect on the Milled Rice Colour value

Increase in initial steaming temperature and steaming time resulted in gradual increase in head rice yield. The initial soaking temperature and soaking time had more effect on the Breakage Ratio than the steaming time.

The current research result could be used by rice processors in Nigeria to improve the physical attributes of milled FARO-44 and hence improve the economic value of local rice varieties as well as discourage the consumers from seeking imported/foreign rice in preference.

\section{REFERENCES}

[1.] Emodi, I. A., andMadukwe, M. C. "A review of policies, acts and initiatives in rice innovation system in Nigeria", Journal of Agricultural extension, 12(2) (2008).

[2.] Chaudhari, P. R., Tamrakar, N., Singh, L., Tandon, A., and Sharma, D. "Rice nutritional and medicinal properties: A", Journal of 
Pharmacognosy and Phytochemistry, 72), (2018), 150-156.

[3.] Enwerem, V. A., and Ohajianya, D. O."Farm size and technical efficiency of rice farmers in Imo State, Nigeria". Greener Journal of Agricultural Sciences, 3 (2), (2013), 128-136.

[4.] Ohia, C., Bakarey, A. S., and Ahmad, T. "COVID-19 and Nigeria: Putting the realities in context". International Journal of Infectious Diseases (2020).

[5.] Bassey, E. E. "The Federal Government of Nigeria Proposed Ban on Rice Imports in 2015: A Task for Rice Breeders. Crop Science Society of Nigeria: Second National Annual Conference Proceedings" (2015).

[6.] Dzever, D. D., andAyoola, J. B. "Can Nigeria Sustain Ban on Rice Importation Overtime? Analysis of Its Determinants on Agri-Business Development in Commercial Rice Production and Processing (1991-2015)". (2017) (No. 2223-2019-1712).

[7.] Daramola, B. "Government policies and competitiveness of Nigerian rice economy". Rice Policy and Food Security in sub-Saharan Africa, (2005), 125.

[8.] Himmelsbach, D. S., Manful, J. T., and Coker, R. D. "Changes in rice with variable temperature parboiling: Thermal and spectroscopic assessment". Cereal chemistry, 85(3), (2008), 384-390.

[9.] Koh, E., andSurh, J. "Parboiling improved oxidative stability of milled white rice during one-year storage", Food science and biotechnology, 25(4), (2016),1043-1046.

[10.] Milltec Machinery. Parboiling and Dryer Systems (2015). Retrieved from http://milltecmachinery.com/wpcontent/uploads/2018/10/parboiling-anddryer-MILLTEC-MACHINERY-LTD.pdf

[11.] Ayamdoo, J. A., Demuyakor, B., Dogbe, W., andOwusu, R. "Parboiling of paddy rice, the science and $p$

[12.] erceptions of it as practiced in Northern Ghana". International Journal of Scientific and Technology Research, 2(4), (2013), 13-18.

[13.] Islam, M. R., Shimizu, N., and Kimura, T. "Quality evaluation of parboiled rice with physical properties", Food Science and Technology Research, 71), (2001), 57-63.

[14.] Danbaba, N., Nkama, I., Badau, M. H., Ukwungwu, M. N., Maji, A. T., Abo, M. E., andOko, A. O. Optimization of rice parboiling process for optimum head rice yield: a response surface methodology

(RSM) approach. Focus, 18, (2014), 19.

[15.] Yousaf, K., Kunjie, C., Cairong, C., Abbas, A., Huang, Y., Arslan, C., and Xuejin, Z. "The optimization and mathematical modeling of quality attributes of parboiled rice using a response surface method", Journal of Food Quality, (2017).

[16.] Ogunbiyi, M. O., Adejumo, B. A., Gbabo, A., andChinma, C. E. "Optimisation of Parboiling Process using Response Surface Methodology (RSM) to improve the Physical Properties of Parboiled Milled Rice" (2018).

[17.] Widyasaputra, R., Syamsir, E., and Budijanto, S. "Optimization of Process Parameters of Parboiled Black Rice Using Response Surface Methodology", Current Research in Nutrition and Food Science Journal, 71), (2019), 102111.

[18.] Taghinezhad, E., RasooliSharabiani, V., andKaveh, M."Modelling and Optimization of Hybrid HIR Drying Variables for Processing of Parboiled Paddy Using Response Surface Methodology". Iranian Journal of Chemistry and Chemical Engineering (IJCCE)(2018).

[19.] Propcom. Report on financial analysis of rice Parboiling/processing systems in bida Area, Niger state, Nigeria. Submitted By National Cereals Research Institute (NCRI), Badeggi (2006). Retrieved from http://www.propcommaikarfi.org/wpcontent/uploads/2013/08/6-FinancialAnalysis-of-Rice-Parboiling-ProcessingSystems-in-Bida-11-061-1.pdf.

[20.] Bello, M. M., Abubakar, M. S., andLawan, I. "Rice parboiling practices and technologies in Kano state", Journal of Engineering and Technology Vol. 10 (2), (2015), 52-59.

[21.] Ndindeng, S. A., Manful, J., Futakuchi, K., Mapiemfu-Lamare, D., Akoa-Etoa, J. M., Tang, E. N., and Moreira, J. "Upgrading the quality of Africa's rice: a novel artisanal parboiling technology for rice processors in sub-Saharan Africa", Food Science and Nutrition, 3 (6), (2015), 557-568.

[22.] Agidi, G., Liberty, J. T.,Jibrin, A., andAlhassan, T. M. "A Tiltable Discharge Paddy Parboiling System", International Journal of Engineering Innovations and Research, 4(5), (2015), 672.

[23.] Gbabo, A., Abdullahi, L., and Kuku, A. M. "Design, Fabrication and Testing of Improved Traditional Rice Parboiler identification of common molecular subsequences", International Journal of Engineering and Technical Research, 2 (9), (2014), 331-338. 